MedieKultur | Journal of media and communication research | ISSN 1901-9726

Article - Theme section

\title{
Sports broadcasting journalism and the challenge of new media
}

\section{Kirsten Frandsen}

MedieKultur 2012, 53, 5-21

Published by SMID | Society of Media researchers In Denmark | www.smid.dk The online version of this text can be found open access at www.mediekultur.dk

This article explores the challenge faced by established media organisations integrating digital media in their production. Using a case study of a Danish broadcaster's use of blogs in their coverage of major sports events, it is argued that the challenge is strategic in a broader sense, as the move to digital platforms is influenced by economic, organisational as well as conceptual parameters for roles. It is argued that in order to understand the potential and challenges of this case, the peculiarities of the role of sports journalists in broadcasting have to be taken into consideration. The case illustrates how their distinctive engagement with their topic and the audience makes some of them more prone to work for pleasure and produce for the digital platform on very unclear conditions, just as it influences the interaction that takes place in the blogs in various ways.

\section{Introduction}

The current changes to the media environment caused by digital media are evolving, and established media organisations and one of their constitutive institutions, namely journalism, are currently undergoing significant changes as the organisations adjust to new conditions. Still, discussions about the challenges involved when policy decisions are to be implemented in a specific organisational setting with a certain journalistic culture are rather limited. In journalism research, contributions have focused on how journalism in general 
responds to new media and how the journalistic role as such is challenged by the new conditions. From a media research perspective, some contributions have focused on the specific strategic, economic and organisational aspects of the transition. But, on the whole, our understanding of the challenges faced on the organisational and individual levels is still limited, in particular because the approaches mentioned above are often founded on either generalised, hegemonic or idealistic notions of journalism or on a sociological approach to media stressing the importance of adjustments on the policy and management levels. The overall aim of this article is to contribute to this field by implicitly arguing that the challenges faced by the established media and journalism are strategic in a broader sense, as it is not just a matter of capturing market shares on new platforms for commercial reasons, but also a matter of accommodating organisational structures and role conceptions.

The background for this argument is a case study of a Danish broadcast organisation's use of blogging in connection with coverage of major sports events. Using a qualitative bottom-up approach and focusing on an aberrant case like sports broadcasting, which has a repertoire of roles distinctively different from the hegemonic understanding of the journalistic role in general, both substantiates and broadens the scope of the discussion. Methodologically, the study applies a sociological approach to media, combining theoretical understanding with empirical investigation of how organisational changes and individual resources and motivations in combination inform the development of new forms and practices in media production today. Accordingly, the case study is based on a triangulation of data consisting of document analyses of official government reports and newsletters from the broadcaster TV 2 in the period 2005-2009, interviews with mid-level managers in the organisation and an analysis of content and interaction in blogs on the broadcaster's website written by employees at the sports department at TV 2 during their coverage of two strategic important sports events: the European Championship in Women's Handball in 2008 and the World Championship in Men's Handball in 2009.' In addition, the analysis is also informed by informal discussions with journalists from the sports department and blogs from the coverage of the Tour de France in 2009 and 2010.

\section{A transition of strategic importance}

Digital media have attracted much interest from researchers because they have been considered the facilitators of the advent of a new participatory culture (Jenkins, 2006) in which consumers become producers and the autonomy of individuals has been enhanced (Benkler, 2006; Bruns, 2008). Thus, initial research in this transition has in particular been preoccupied with the audience's transformation to producers and not with transformations within traditional media production. Inasmuch as these contributions underline how these new kinds of producers are driven by motivational forces other than market orientation and by a particularly strong interest (Benkler, 2006, p.13), one could say that this research is nourished by oversimplified notions of the drivers behind both producers and audiences within traditional media. 
Regarding production in particular, the current transition has been characterised as a battle between an old industrial model of production driven by a liberal market orientation and a networked information economy driven by forces other than pure market logics (Benkler, 2006). This points very directly to the overall strategic importance of the transformation of the established media. In this new environment, traditional boundaries between market and non-market actors and between professional producers and amateur producers are constantly blurred. On the level of the individuals in production, this blurring between working for money and working for pleasure has been a distinctive feature of the working culture within the cultural industries and in particular within the television industries for more than a decade (Ursell, 2000). But the ongoing transformation seems to accentuate this and constitutes a core in the conception of the challenge at hand, as digital media open up for far more decentralised individual communicative actions - also for those employed in traditional media organisations.

Nevertheless, recent research has produced empirical evidence of how traditional media organisations and journalists use a wide range of different strategies to secure themselves an audience and a position in the media landscape for the future (Moe, 2008; Krumsvik, 2006), and some have even documented a considerable degree of resistance and organisational inertia towards integrating digital media and their interactive affordances in news production (Rebillard \& Toubul, 2010; Krumsvik, 2006; Schultz \& Sheffer, 2007). Yet, the main focus has been on news journalism, whereas the variety in terms of organisations, communicative functions, role conceptions and subject matters within journalism itself have not been addressed as parameters in their own right - except for by Schultz and Sheffer, who touch very briefly upon these issues. It is this perspective which will be clarified below.

\section{Sports broadcasting and new media: A strategic perspective}

The integration of digital platforms, both in terms of communicative practices and the development of new business models with longer value chains, has been a key concern in the television industry for several years. One of many new initiatives taken in order to comply with a new media landscape has been to strengthen interaction with the audience. In a Danish context, the public service broadcaster TV 2, which has held a dominant position on the Danish television market since the early nineties, was a "first-mover" in terms of the use of blogs in relation to broadcasting.

In the current case, the focus will be on a specific category of the journalistic bloggers at TV 2, namely those working with sports broadcasting who have been blogging in connection with their organisation's coverage of major sporting events. Their blogs have been among the most successful in terms of response, and the case exemplifies both a very specific and a highly strategic connection between traditional broadcasting activity and interactivity on the Internet. 
In the television industry, owning the rights to cover certain major, international sporting events is well known for its strategic significance in promoting a positive image as a national, unifying broadcasting institution, or as a high-quality broadcaster of premium content, and above all, for securing subscribers and a certain share of viewers from commercially relevant target groups. But still, sporting events, unlike many other forms of media content, are closely linked to specific time frames - owing to a game's unpredictability - and television has maintained a strong position in the distribution of this form of content. Contrary to many expectations of the 1990s, television therefore still holds a dominant position when it comes to the "real-time" experience of the action on the field (Boyle \& Whannel, 2010). At the same time, this audience engages with sport in new ways, using new media, such as mobile phone technology and the Internet, to supplement television, and thereby augment their sports experience both at home and at the stadium. In particular, football and international sporting events are considered "killer content", which, owing to the audience's strong relationship with it, has the capacity for "persuading consumers to abandon existing patterns of consumption and adopt new technologies and products" (Küng, 2008, p. 85). In other words, broadcasting from such an event makes up an exceptionally strong basis for a broadcaster, for communicative or commercial reasons, to launch new services or communicative products on a digital platform.

The capacity of certain sporting events to help both old and new players to survive or establish themselves in a very competitive television market means that huge sums have been paid for the rights to cover the top leagues and top events of the most attractive sports. This investment has fundamentally changed the relationship between broadcasters and sports organisations (Fortunato, 2001), implying mutual obligations standing for several years. But, based as it is on live transmissions of games, there is a fundamental uncertainty regarding the quality of the product. The broadcasters therefore automatically put the event or leagues that they have bought rights for high up on their agenda, and they try to strengthen the value of the product and exploit their rights to their limits. Above all, broadcasters' blogging activities in relation to these events must be understood from this general strategic perspective. Combining live transmissions and journalists' communications with segments of the audience on broadcasters' websites is just one illustration of an activity that may enhance the value of the investment in several ways. In economic terms, it creates a longer value chain on sunk costs (Küng, 2008, p. 54) without requiring further investments in rights to cover the event on the Internet. In communicative terms, the media organisation may take advantage of some of the dominant characteristics of sport as content - namely, that sports, particularly in the form of major televised sporting events, have a unique ability to generate strong feelings of community among the audience, and that sports in general have always been strongly embedded in passionate discussions among fans. And these discussions are moving along at increased speeds as digital media are offering different actors a whole range of new platforms for communicating and exchanging information (Whannel, 2002; Boyle \& Haynes, 2004). Seen from a traditional 
broadcaster's perspective, blogging by well-known television hosts and reporters, which builds on existing and well-established relationships with mass audiences, stands out as an appropriate strategic tool for maintaining an increasingly endangered status as a crucial, influential and commercially relevant player.

\section{Blogging and journalism: Questions about roles and power}

Blogs have served as catalysts for sweeping discussions and a state of crisis within journalism in general concerning journalists' apparent diminishing role as gatekeepers in the public debate. In the current case, blogs were received on a slightly different basis, but the actual implementation in the broadcasting organisation still partially reflects the more general challenges that journalists and their management are facing in the adjustment to a more complex media environment with new communicative forms. As a communicative form, a "blog" can be defined as:

[...] a Web-based form of communication that includes frequent updates and a series of archived entries made in reverse chronological order. Blogs often provide commentary or news on a particular subject [...] (Schultz \& Sheffer, 2007, p. 63)

As a web-based format, a blog allows for direct interaction and dialogue between individuals in a public space, and thus it potentially challenges the work routines and roles of a professional communicator working on the basis of traditional broadcasting and mass communication. New skills are required, for example, when a television host suddenly finds himself interacting directly on a blog with individuals from his mass audience.

Two aspects of blogs have recurrently been addressed in the discussion of blogs among journalists and can give us a hint of how they also challenge the profession. First, most of them are published by individuals who very rarely receive compensation. Second, they manifest a more unfiltered, direct, "personal voice". Strong professional ideals making claims for the necessity to apply objectivity or neutrality in order to serve a common public interest in journalism and to survive commercially and as a profession are thus at stake. The occupational and professional roles of journalism have been shaped by the organisational necessity of addressing a broad audience in order to survive commercially. For Lowrey, the crucial difference between traditional journalism and blogging is precisely this organisational framing of the production: "Differences in content, work processes, tone values and format are symptoms of this underlying structural difference" (Lowrey, 2006, p. 480). In the current case, this means that blogs created by television professionals differ from personal blogs created by private individuals, but they also have to maintain some of the features characterising and constituting the blog as a specific kind of communication. Balancing the organisational interests and the communicative expectations constituting the blog as a specific mode of communication seems to be a key challenge. 
Both Rosen and Lowrey argue that much of the journalistic discussion about blogs has been unproductive, having only addressed whether bloggers live up to journalistic standards and are to be considered journalists, instead of asking what blogging can do for journalism. For Rosen, the development of blogs is not automatically synonymous with journalists' loss of influence or reputation, but will pave the way to a new contract between news providers and news consumers (Rosen, 2005, p. 2). Lowrey is primarily in agreement with Rosen, arguing that blogs are to be considered a new journalistic tool to be used, so the media can be there when the audience is ready. Blogs have the potential to change journalistic practices, but until recently changes seem to have been minor in terms of methodology of production or perception of role change. For many journalists, blogs have become important sources of information and ideas, but in general, blogs as journalistic tools are met with resistance because they threaten basic routines, habits and skills. Schultz and Sheffer's (2007) explorative, quantitative and qualitative study of blogging among American sports journalists confirms that this group shares a predominantly negative attitude towards this new activity. Schultz and Sheffer emphasise that this attitude does not merely represent a flaw in a profession's ability to readjust to new conditions. Instead, they point out that for many of the journalists in their study, blogging represents "more work for the same money", and they further stress that the resistance is most marked among the oldest and most experienced journalists. They also indicate the responsibility of management, since the majority of their respondents began blogging at the instigation of management. Management at the media outlets has been eager to push journalists into blogging for strategic and economic reasons. But according to Schultz and Sheffer, this same rush has meant that the management often fails in the implementation:

[...] the rush to blog has been made with little or no consideration of how this emerging technology is being implemented or its consequences for media managers and workers. (Schultz \& Sheffer, 2008, p. 1)

Their findings suggest that, from the journalists' perspective, management often fails to communicate its goals and help them navigate the new conditions. In particular, Schultz and Sheffer stress the importance of guidelines and positive feedback as crucial for getting journalists to share management's visions and become more self-motivated:

Managers should clearly outline practices, standards and expectations related to the implementation strategy: This is especially important given the uncertain nature of implementing a new media technology. Work roles and specific implementation details are still being worked out and may be confusing to rank-and-file journalists. (Schultz \& Sheffer, 2008, p. 10)

In general, most of the discussion about blogs and journalism partly outlined above has been framed by professional, hegemonic understandings of journalistic standards rooted in traditional political news journalism and print media. Indeed, this only partly applies to Schultz and Sheffer's contributions. Although they argue that their findings represent gene- 
ralised patterns in journalism, their final discussion also indicates that they experienced a low level of response, and that the conception of blogs and journalistic roles may be more nuanced. First, they mention that sports journalism is a "distinct and unique" form of journalism, but do not elaborate further on this. Instead, they stress that these journalists have to be considered on par with other journalists, as they "share many similarities with other journalists in terms of training, reporting and production techniques" (Schultz \& Sheffer, 2008, p. 10). Second, even though for the most part their analysis has not shown statistically signifcant differences in the attitudes between journalists from different media, they stress that television, radio and newspapers are distinct entities. Therefore, they identify this as another perspective to be elaborated on in future research on the role and purpose of blogging.

\section{Sports journalism and sports broadcasting: a different basis for blogging?}

To obtain a more nuanced understanding of the communicative challenges of and potential for blogging in connection with sports transmissions, it seems crucial to focus on the more distinct features of sports broadcasters' roles as communicators. First, it is important to acknowledge that the role of sports journalists deviates in some ways from those of other journalists. Second, the role of those involved in sports broadcasting is different from that of their colleagues in print media. Dealing with sports journalism, and in particular with sports broadcasting, therefore twists the discussion of blogging in several ways. Owing to the nature of the field and the medium with which they are dealing, these professionals have a different relationship with their audience (Frandsen, 2008, 2010), and sport as content engenders a level of passion and commentary very similar to that associated with blogging (Schultz \& Sheffer, 2008).

Sports journalism has always been considered "not real journalism" or the "toy department" in the professional hierarchy of journalism, in that it is preoccupied with a subject that is not strictly political, nor directly related to public affairs or high culture. Sports journalism is focused on the coverage of events, where games, competition and rivalry, and the experience of winning and losing are key elements (Boyle, 2006, pp. 62-63). Consequently, the journalistic practices within this field, in several ways, have not met the professional standards that gradually developed in other areas of journalism. Instead, it has evolved into a territory of its own, wherein the journalists' ability to perform, and express their own passion, excitement and judgement have been crucial for establishing and sustaining a relationship with the audience that is based on a shared fascination. Historically, sports journalists in print media have been allowed and expected to express subjective opinions and feelings when reporting or writing commentaries. Thus, sports journalists may have another starting point for blogging, to which a more direct, unfiltered and personalised mode of expression is central.

Whether sports broadcasting is a form of sports journalism is much disputed, as broadcast media coverage, owing to its immediacy, offers the audience a high level of live experience, colour and drama (Boyle, 2006). Television's ability to visually convey the experience 
of the game to a mainstream audience has changed the role of journalists even further. Nevertheless, Boyle argues that sports broadcasting is to be considered a particular form of journalism, and he stresses the close relationship between sports journalism in broadcasting and in print media. Until the early 1990s, television only covered the actual competition and left the event as soon as the match was over. Print media therefore had a role in building up a television audience with their pre-game coverage, thereby contributing to a wider understanding of the cultural and social significance of sports through their pre-and post-game coverage. Until the 1990s, most broadcasters were strictly focused on conveying the action and dramatic dimension of the event to the viewers by way of a balanced but engaging commentator who would both contribute information and drama and act as a parasocial partner for the viewers. The fact that the viewer witnesses the action him/herself on-screen at the moment it occurs influences the role of the broadcaster. The relationship with the audience becomes more symmetrical and more social because the journalist is not necessarily in possession of more knowledge of the game, but has an institutional responsibility for holding the viewer's attention. This establishes another platform for more direct interaction with the audience for a blog.

For many years, most European broadcasters were public service institutions that had to pay attention to mainstream audiences, which had an impact on sports broadcasting. Apart from patriotic interpretations, analysis and subjective commentary were to a great extent left to their colleagues at the newspapers. Today, broadcasters now use a wide range of expert commentators to provide analysis and commentary both during the transmissions and in their pre- and post-game programmes. The broadcasters seek to exploit their expensive rights to the limits, and extract from them the maximum number of hours of programming and other kinds of output. Blogging is to be understood in this perspective: now allowing not just the experts but also the broadcast professionals to voice their interpretations and analyses of the games.

\section{TV 2: an organisation marked by change}

In the early autumn of 2006, the Danish public service broadcaster TV 2 announced a new strategic focus on blogs. This initiative came in the wake of a whole range of new activities launched during the spring and summer of 2006 by a newly appointed executive management whose initiatives were informed by the Danish liberal government's decision to sell the publicly owned broadcast organisation to a private investor. The new management considered TV 2 to be a very well established, strong brand with a dominant position on the Danish television market. But in order to "future-proof" this status - prepare the organisation for sale and increase its value - it was considered important to upgrade the organisation's activities. In particular, the new executive manager focused on improving the organisation's activities on the Internet, primarily for commercial reasons. Improving revenues was an all-important goal for him, and in order to finance the station's investments 
in a radio station and new television channels, the organisation needed constantly increasing revenue from advertising and user fees, and from a wider range of revenue sources. As part of a new strategic focus on improving the revenues from all platforms, a new position as commercial manager for interactive media was established, as was the goal of making $T V$ 2's website, tv2.dk, among the three most visited Danish websites. This goal had to be reached before the end of 2006. Increasing the traffic to the website was a prerequisite for making a profit on the website, for developing promising new commercial products, such as cross-media solutions for advertisers, and for exploiting other kinds of anticipated synergies among television, the Internet and mobile phones.

\section{Creating monetary value and symbolic claims}

User-generated content was designated as one of the means for meeting these ambitious strategic goals set by a very enterprising new executive management keen on rapidly making perceptible changes in the organisation. To set this in motion, in September 2006 TV 2 launched a series of blogs authored by the executive managing director and some of the station's best-known hosts, editors, reporters and commentators of popular programmes. Blog. tv2.dk had already been launched in July 2006, but attracted only minimal interest and traffic. However, at the beginning of September 2006, the executive manager created a personal blog as a follow-up to a controversial documentary broadcast on the main channel, and shortly after that, several other journalists also began blogging. In an official announcement in TV 2's September newsletter, the content manager for interactive media emphasised that the blogs authored by TV 2 executives and journalists would serve the strategic purposes of the organisation. According to him, their function was to enhance the organisation's communication with its audience, both quantitatively and qualitatively. The strategic interest was primarily related to blogs' potential to engage the organisation and the audience in a dialogue, resulting in more traffic to the website as a whole. But it was also stressed that blogs would provide the opportunity for TV 2 to influence the public agenda and debates already taking place on the Internet. In a wider sense, it was argued that what were identified as the "personal blogs" of TV 2 journalists could have a positive impact on the broadcaster's image by signalling organisational honesty, a personalised organisation and openness to criticism.

The idea was that blogs created by the stations' celebrities combined with explicit references to these blogs in programmes or in specific television spots would boost the audience's interest in blogging and subsequently drive more traffic to the website by encouraging the audience to read and create their own blogs at blog.tv2.dk. At the end of October 2006, TV 2 announced that the strategic goal of becoming one of the three most visited Danish websites had been achieved, and that blog.tv2.dk had attained the position of the most used blog site in Denmark. 


\section{Blogging: a matter of commitment and positioning}

As discussed above, the new executive manager at TV 2 personally took the lead in this process, implementing his idea through personal practice. From 2006 on, the journalists were encouraged to blog. However, it is important to note the way in which this was presented to them. This new task was not defined as part of their contractual duties, but presented via the mid-level managers as a desirable initiative that, in the long run, would benefit both individuals and the organisation as a whole. One of the managerial tools intended to motivate journalists to take on this new workload was an award to be presented to the reporter whose blog was the first in the organisation to reach more than 100,000 visitors. Symbolic acclaim for those who successfully complied with the new task was among the explicit managerial tools used during the implementation phase. Articles were published in the newsletter, describing how high-status journalists had overcome their former attitudes of resistance and scepticism towards blogs and were now profiting from this new form of contact with the audience. At a more indirect level, the generally competitive spirit among journalists contributed to the implementation of blogs. Some journalists began comparing the numbers of visitors to their blogs. Being effective in creating a lot of traffic and responses on the blog within a short while was a focus among some of the most well-known hosts and caused both publicity and banter among the journalists. Generally speaking, the willingness to take on new tasks and the ability to generate traffic to a blog came to function as important symbolic signs of personal commitment to the organisation and an ability to adjust to new circumstances:

Passionately plunging himself (the executive manager) into the blog universe was indeed a very perceptible way of marking his own interest for this field to the employees [sic], meaning that everybody who wished to show their support for him and his ideas knew that they should create blogs. (Interview, John Jäger, deputy manager of editorial staff, TV 2 Sport)

The new top-level management was extremely eager to make rapid changes, and therefore also caused a lot of controversy in the organisation. In this particular organisational atmosphere of change and uncertainty, creating a blog became an important manifestation of the art of the individual, indicating both commitment and support for the top-level management's visions. Thus, the organisational situation initially created considerable activity, but also temporarily suspended further considerations regarding communicative goals and strategy. What is perhaps more important is that as a result of these specific circumstances, resistance towards blogs, arising from their capacity to challenge and change existing work routines, never acquired a strong, unified voice among the journalists.

\section{Communicative visions abandoned}

One year after this fast-paced start, a task force of employees started a more systematic articulation of the communicative goals of blogging. But at that time, the visions and focus of 
top-level management had changed, and consequently a gap between the strategic visions and the organisation's willingness to allocate resources to blogging became apparent:

It was strongly emphasised that blogging was an activity meant to take place in our spare time [...] and my conclusion was that this was setting up severe limitations regarding the potentials to use it as a strategic tool.[sic] (Interview, John Jäger, deputy manager of editorial staff, TV 2 Sport)

Nevertheless, guidelines for blogging activities were formulated, stating that the blogs were "personal blogs", and as such permitted the journalists to express personal opinions, apart from those opinions that were strictly political or related to issues concerning the broadcaster's official policy. Blogs that gratified the audience's curiosity regarding the lives and thoughts of the station's most popular hosts and reporters were particularly encouraged, as they generated the most traffic. These conditions meant that blogs could only serve to strengthen an overall image of the broadcast organisation and its journalists as fundamentally open to and interested in digital media. Most of all, in strategic terms, it became clear that blogging was still mostly about generating as much traffic as possible using limited resources.

\section{Making the most of existing skills}

From the journalists' perspective, the introduction of blogs has involved uncertainty for several reasons, and the journalists in the sports department have had very different approaches to it. For them, the blog represented a challenge because it is dialogic in nature. Some of them were very enthusiastic about this new platform, and in fact those involved in sports broadcasting have been among the most active and popular bloggers (in terms of number of visitors and comments) in the entire organisation. The person who first reached more than 100,000 visitors with his blog was a relatively young sports reporter. He was quite experienced in establishing dialogic relations with the audience, having been a very popular host on one of TV 2's supplemental channels, TV Zulu, which from 2000 to 2007 had succeeded in attracting a new, young audience with its transmissions of American football matches. In these programmes, he and an expert had become very popular among young viewers, devising quizzes involving the viewers and communicating directly with them via e-mail during the programmes. Clearly, he had a well-established relationship with what may have been the most motivated segment of the audience upon which he could build.

Other journalists were more sceptical, and part of their resistance was related to the organisational situation, and receded as blogs faded from the top-level manager's agenda. As a result, some of those who had initially refused to experiment with blogs actually began blogging after a while, exploring different ways of using them. For instance, the former manager of the sports department, who hosted some of the main channel's very popular handball transmissions, used his blog to communicate with viewers during an important international match, thus exploring blogs' potential for sustaining and strengthening 
a host's relationship with a segment of the audience. Also, one of the editors in the sports department caused something of an uproar in professional circles when he used his blog to comment on the coverage of televised sporting events in the print media. The point is that when blogs lost their internal symbolic significance in the controversy surrounding the toplevel manager, there was a boom in their use, both in terms of quantity and quality.

Despite the fact that management did not want to invest time or money in blogs, many of those involved in sports broadcasting created blogs anyway. Part of the explanation is that many of TV 2 Sport's employees are fairly young and more positively inclined towards digital media. But another explanation is that blogging fits in with the competences and skills required in sports broadcasting. Sport involves its audience emotionally, as must those who deal with it professionally. In particular, this applies in the case of television, which is focused on conveying live action. Here the audience and the professionals view the same actions simultaneously, and their relationship is based on a shared, emotional presence and fascination with the same great moments, and this is a productive, underlying basis for engaging in dialogue on a blog:

\footnotetext{
Our product involves many feelings. Sport is a kind of entertainment where different opinions about the competitors as either divine creatures or bastards are allowed. I think, this easily applies to the blog universe. Many of our employees have been well prepared to respond to this [...] Many of our employees deal with sport as their profession, but they also have a great passion for it. And therefore they also have opinions about it. [...] Therefore they can benefit from blogging in their spare time, focusing on issues and expressing opinions that they cannot deal with the same way when making their stories for our programmes. (Interview, John Jäger, deputy manager of editorial staff, TV 2 Sport)
}

In other words, the boundary between "working for money and working for pleasure" has never been clear-cut or relevant for a group among TV 2's sports journalists, and this circumstance as well as the particular skills required for sports broadcasting form a different background for engaging in blogging - even as a spare-time activity.

\section{Dialogue on distinctive terms}

For some of the journalists, blogging has been considered problematic because they have felt quite uncertain regarding the type of topic to be addressed and the way to address it. Because of this, and the fact that blogging really is "more work for no money", several journalists have refrained from blogging or have only been active for a very short while. Also, a small number of those who began blogging have quit because they felt very uncomfortable with some of the audience reactions, which were formulated in a threatening, offensive or crude, emotional tone. Compared to the very polite tone and social conventions associated with private, personal blogs (Lomborg 2009), it is obvious that the premises for establishing a relationship with the audience are different for TV 2 journalists, even though their blogs are considered "per- 
sonal blogs". For instance, a comment on a newly appointed reporter's blog during the Tour de France 2010 starts with the statement: "Shut up you fool, I'm sick and tired of listening to you".

Every blogger has to work to earn and build up an audience. But the comments on the blogs of TV 2 journalists demonstrate that they still hold a privileged position in the communication with the audience. Audience response indicates that these bloggers are essentially considered representatives of $T V 2$, and from some this prompts an admiring and respectful attitude, whereas from others it elicits an oppositional, almost insulting attitude. No matter how much the blogger writes as a private individual in his or her spare time, he or she is addressed as part of a powerful institution. Furthermore, the premises for communicating are different because sport culture is often characterised by insulting, emotional utterances and anti-authoritarian attitudes. For fans, watching sports transmissions often involves shouting and yelling from their safe position on the couch in the living room (Frandsen, 2010). When sports professionals create a blog, they may come in direct contact with this culture, as the viewers may carry their attitudes and communicative behaviour from the viewing situation to the blog. Particularly for those journalists who engage in critical, investigative journalistic work, revealing the dark side of professional sport, or those who do not have an established and unproblematic relationship with the viewing audience, blogging constitutes a great communicative challenge. The young reporter mentioned above was very active on his blog during the Tour de France, but reader response was very modest, and many of the comments were highly critical of his competencies as a blogger and of his knowledge of and approach to biking. It would appear that a face or voice that is unknown to television viewers while speaking from within the institutional framework makes it difficult to succeed in getting numerous comments and engagement in dialogue.

\section{Successful performances of existing roles and relationships}

Finally, if we turn to the communicative practices of some of the most successful of TV 2's bloggers in terms of number of visitors and comments, it becomes evident that blogs may not change their communicative role. Instead, the relationships with the audience in their blogs lie very much in line with the relationship established through television. In addition to having relatively large numbers of posts during the coverage of major events, the successful blogs are all authored by men, and build on a distinct presence in televised, live coverage. These three blogs are those of an expert commentator, a reporter and a presenter who anchors the live programmes, and they demonstrate in distinct ways how blogging by television professionals is framed by the institutional status and performative role that they have on television.

The expert commentator has a part-time contract with $T V 2$, where he acts as an expert during live transmissions of handball matches involving both the Danish league and international championships. In contrast to those with a full-time contract, part of his job is to express his opinions about handball on all relevant platforms. He has a background as former coach and former sports editor at a local Danish newspaper. In connection with 
major events, he posts a commentary one to two hours after TV 2's transmissions, evaluating and judging the performance of players and coaches during the game. These commentaries are non-dialogic in form and content. He publishes his analysis just as he might do in a newspaper. He never responds to the comments to his posts. Nevertheless, audience response is intense and prompt. In the comments, the audience addresses the expert directly, responding to his opinions and frequently expressing their joy or frustration with his comments during the transmission. Thus, this serves as a platform for the audience members to demonstrate their own expertise. In connection with this, a recurrent issue is addressed, namely the expert's competencies as expert in general, and as an expert commentator on television in particular. The lack of response from the expert is never commented on - this contrasts with what is seen on some of the other blogs, where expectations of a response are occasionally articulated. Instead, the posts facilitate comments, often starting a discussion among the audience. This blog is successful because it facilitates interaction among the audience and gives individuals a platform for demonstrating their expertise before an engaged and competent audience. Reactions from this audience enhance the experience of personal competence.

The reporter has a full-time contract with TV 2 and is often present for the viewers at major events, holding short interviews with the athletes or coaches just before and after the match. He is the type of reporter who asks the much-criticised question, "How do you feel now?" His role on television is to represent the mainstream audience "on the spot", and in his blog he is careful to act consistently with this, expressing a very humble and sometimes naive attitude - asking questions and writing in a very enthusiastic but also dialogical way. He explicitly states that he is not an expert, that he is driven by a fascination with the game and the athletes, but would like to involve experts among the audience in the discussions on his blog. In this way he sets himself on par with those viewers who do not feel competent enough to engage in dialogue with a high-profile expert. When he reports for major events, he explicitly states that his blog will bring the audience behind the scenes and closer to the athletes. This blog facilitates discussions among the audience, just like the expert's blog, but is also characterised by a human angle on the athletes, expressions of emotional enthusiasm and relatively frequent responses from the reporter to a quite diverse range of comments and questions from the audience.

In many ways, the blogs of both the reporter and the expert represent two distinct types of relationships between the blogger and the audience, one based on a shared emotional experience and fascination, and the other on a shared experience of being competent readers of a game. In the third blog, created by the presenter, the relationship is not as easy to identify, in that he seems to get responses from the audience for many and much more diverse reasons. His blog demonstrates that hosting is indeed a juncture of different relationships, which makes blogging a huge challenge, as it has to meet highly diverse audience expectations. As a host, he is the official face of the station and responsible for establishing the primary contact with the audience, keeping their attention on that channel and making 
them feel both comfortable and excited about the games that are covered. In person, he connects the viewers, the channel and the sporting event, eroding their spatial separation. In his posts, he emphasises that he and the viewers have a joint interest in the events, and he explicates the personalised contact with the viewers, finishing some of his posts with "see you" and using the first person pronoun, such as in, "I think". His posts are sometimes pregame comments that in various ways build up excitement about a game that he and the viewers are supposed to experience together later. Or his posts may consist of post-game comments with which he pursues issues recurrently addressed by the commentators during the transmissions, asks the viewers about their points of view, and in this way creates debates with and among the viewers. One of the challenges of this blog is that in viewer comments he is addressed in different roles. He is addressed as their primary contact with the station as a whole and as responsible for all aspects of the programmes and digital services offered to them. This means that the audience sometimes uses this blog to ask questions about rules in manager games on TV 2's website or to express opinions about technical aspects of the visual productions, about policy decisions and about the commentators. The host answers some of these comments, sometimes emphasising that he has difficulty finding time for this and that direct dialogue must not be expected. In his answers, he speaks as a representative for the entire organisation, and he emphasises the organisational framework behind the blog. For instance, he responded to a highly critical comment about an expert commentator by saying: "He is contracted as an expert. [...] We are his employer".

\section{Concluding remarks}

In this article I have discussed the strategic challenges that established media, rooted in old production models, and journalists in sports broadcasting face when they move to the digital platforms and start blogging. Seen from a theoretical perspective, the discussion of journalism and blogs has addressed the issue on a very general level and took its starting point in a hegemonic understanding of journalism. It has been argued that in order to understand the specific challenges and strategic potential of blogs, the discussions need to take into consideration that sports journalism is a particular form of journalism and that sports broadcasting is a particular form of sports journalism. This constitutes a unique basis for blogging with the audience in connection with coverage of major sporting events. The bottom-up perspective demonstrates how the understanding of the challenge at hand can benefit from a more holistic perspective encompassing managerial, organisational and roleconceptual perspectives. It also reveals how a new media economy based on a blurring of non-market and market-oriented producers is taking form, and in particular it shows how this economy has moved into the organisation itself, leaving the individuals employed in the organisation in a grey area regarding their roles and work conditions.

In the case of the Danish television broadcaster TV2, blogging by the journalists started on the request of a new executive management eager to make changes and improve the 
broadcaster's revenues on all platforms. The close connection between strategic, commercial interests on policy level, a strong internal controversy around the executive manager, and the implementation of blogs resulted in considerable activity. But in the long run, resources have not been allocated to those creating the content - the journalists - and a more systematic discussion of the communicative potential in this kind of cross media communications in connection with major sporting events has been suspended for a period by the dominant commercial strategic interests.

Meanwhile, the conditions for interaction with the audience in relation to coverage of big events have changed as well. The breakthrough of Facebook has had implications for TV 2's digital services, the communicative needs formerly fulfilled by the blogs on TV 2's website now being partially met in other types of communities on Facebook. Still, the broadcaster holds a position among the most popular Danish websites and has recently changed its organisational structures in such a way that they actually facilitate a stronger communicative integration of the Internet and the television platform during major sports events. Until spring 2010, decisions and editorial responsibility regarding television coverage and website content were placed on different persons in two different places in the organisation. Now the editorial responsibility for sports content on both the website and television is held by the same person. Blogs are still made by journalists during big events, but they no longer have the same exaggerated status in the organisation, and paid-for blogs written by sports celebrities have come to play a more prominent role as creators of traffic during periods without big events. During the transmissions from the Tour de France 2011, TV 2 offered coverage for mobile phones and encouraged the viewers to engage simultaneously in debates on their Facebook profile. Sharing the experience, being present on all possible platforms and facilitating communication among the audience are key for a broadcaster in a situation in which the audience is increasingly more fragmented and is multitasking more while watching television.

\section{Notes}

1. In the Danish television market, broadcasting rights to handball have an exceptional strategic status, only surpassed by football in terms of both money and exposure.

\section{References}

Benkler, Y. (2006). The Wealth of Networks: How Social Production Transforms Markets and Freedom. New Haven and London: Yale University Press.

Boyle, R. (2006). Sports Journalism. Context and Issues. London, Los Angeles, New Delhi \& Singapore: Sage. Boyle, R. \& Haynes, R. (2004). Football in the New Media Age, London \& New York: Routledge.

Boyle, R. \& Whannel, G. (2010). Editorial: Sport and the New Media. Convergence: The International Journal of Research into New Media Technologies, 16 (3), 259-262. 
Bruns, A. (2008). Blogs, Wikipedia, Second Life and Beyond: From Production to Produsage. New York: Peter Lang.

Fortunato, J.A. (2001). The Ultimate Assists. Cresskill, NJ.: Hampton Press Inc.

Frandsen, K.(2008). Sports viewing: A Theoretical Approach. International Journal of Sports Communication, 1 (1), 67-77.

Frandsen, K. (2010). Watching Handball Transmissions. Experiences of Autonomy, Competency and Relatedness. Nordicom Review, 31 (1), 53-68.

Jenkins, H. (2006). Convergence Culture: Where Old and New Media Collide. New York: New York University Press.

Krumsvik, A.(2006). What Is the Strategic Role of Online Newspapers? Nordicom Review, 27 (2), 285-297.

Küng, L. (2008). Strategic Management in the Media. London, Thousand Oaks, New Delhi \& Singapore: Sage.

Lomborg, S. (2009). The use of new media as socio-cognitive experience - an enquiry into blogging. Unpublished master thesis. Department of Information \& Media Studies, Aarhus University.

Lowrey, W. (2006). Mapping-the journalism-blogging relationship. Journalism, 7 (4), 477-500.

Lüders, M. (2008). Conceptualising personal media, New Media er Society, 10 (5), 683-702.

Moe, H. (2008). Public Service Media Online? Regulating Public Broadcasters' Internet Services - A Comparative Analysis. Television and New Media, 9 (3) 220-238.

Rebillard, F. \& Toubul, A. (2010). Promisses unfulfilled? 'Journalism 2.0', user participation and editorial policy on newspaper websites. Media, Culture \& Society, 32 (2),323-334.

Rosen, J. (2005). Bloggers vs. Journalists is Over, Pressthink, http://journalism.nyu.edu/pubzone/weblogs/ pressthink/2005/01/21/berk_essy.html. Consulted on May 14, 2010.

Schultz, B. \& Sheffer, M.L. (2007). Sports Journalists Who Blog Cling to Traditional Values. Newspaper Research Journal, 28 (4), 62-75.

Schultz, B. \& Sheffer, M.L. (2008). Blogging from the Labour Perspective: Lessons for Media Managers. International Journal on Media Management, 10 (1) 1-9.

Ursell, G. (2000). Television Production: Issues of Exploitation, Commodofication and Subjectivity in UK Television Labour Markets. Media, Culture er Society, 22, 805-825.

Whannel, G. (2002). Media Sports Stars: Masculinities and Moralities. London: Routledge.

Ytreberg, E. (2009). Extended liveness and eventfulness in multi-platform reality formats. New Media and Society, 11 (4), 467-485.

Other sources:

Newsletters: TV 2 Nyheder 2006-2010

Interviews:

John Jäger, deputy manager for editorial staff, TV 2 Sporten, TV 2

Ricki Melchior, community editor, TV 2

Kirsten Frandsen

Associate Professor, PhD

Department of Aesthetics and Communication - Media Studies

Aarhus University, Denmark

imvkf@hum.au.dk 